\title{
Dinâmica dos Territórios Camponeses em Alagoas: a articulação de famílias assentadas para ampliar a Agroecologia em áreas de reforma agrária
}

\author{
Dynamics of the Peasant Territories in Alagoas: The articulation of families \\ settled to expand Agroecology in agrarian reform areas
}

\author{
José Ubiratan Rezende Santana ${ }^{1}$ \\ Ana Maria Dubeux Gervais ${ }^{2}$ \\ Jorge Luiz Schirmer de Mattos ${ }^{3}$
}

\section{Palavras-chave: \\ Luta pela Terra \\ Camponês a Camponês \\ Territorialização \\ Produção Agroecológica}

\begin{abstract}
Resumo
Este artigo analisa o processo de ampliação da Agroecologia em territórios de reforma agrária e as nuances do acesso à terra por famílias camponesas nos assentamentos rurais. Os assentamentos de reforma agrária são constituídos a partir da organização de famílias camponesas, numa busca histórica pelo acesso à terra e pela regularização legal de seus territórios. Essa alteração no regime de uso e posse da terra tem significado o aumento na quantidade e na diversidade de alimentos produzidos nesses agroecossistemas, sobretudo quando há experiências consubstanciadas na Agroecologia, que é considerada uma ciência no campo da complexidade, utilizada como referência pelos movimentos camponeses para orientar a produção de alimentos saudáveis, locais, e com atenção às culturas camponesas e tradicionais. O estudo envolveu dois assentamentos do Estado de Alagoas, Flor do Bosque e Dom Helder Câmara, localizados nos municípios de Messias e de Murici, respectivamente. Os dados analisados foram obtidos do diagnóstico realizado pelo sistema Radis e de registros do diário de campo. Os resultados indicaram que as famílias inseridas na produção de base agroecológica e orgânica são responsáveis por um incremento na diversidade produtiva de $48 \%$ no Flor do Bosque e 39\% no Dom Helder Câmara, com alimentos produzidos exclusivamente por elas. Identificou-se em ambos os assentamentos a presença de famílias que ainda não detêm a posse legal da terra, mas que produzem de forma agroecológica e orgânica. Tal fato adquire grande relevância, uma vez que isso implica diretamente os desdobramentos da territorialização do campesinato nesses assentamentos.
\end{abstract}

\section{Keywords.}

Struggle for the Land

Peasant to Peasant

Territorialization

Agroecological Production

\begin{abstract}
This article analyzes the process of expanding Agroecology in agrarian reform territories and the nuances of access to the land by peasant families in rural settlements. Agrarian reform settlements are constituted from the organization of peasant families, in their historical struggle for access to the land and regularization of their territories. This change in the land use and tenure regime has meant an increase in the amount and diversity of food produced in these agroecosystems, especially where there are substantiated experiences in Agroecology, which is considered a Science in the field of complexity, used as a reference by the peasant movements to guide the production of healthy and local food, particularly those linked to the traditional and peasant cultures. The study involved two settlements in the state of Alagoas, Flor do Bosque and Dom Helder Câmara, located in the municipalities of Messias and Murici, respectively. The data analyzed were obtained from the diagnosis conducted by the Radis system and from field diary records. The results indicated that the families involved in organic and agroecological production are responsible for an increase in productive diversity, with food produced exclusively by them, with $48 \%$ for Flor do Bosque and $39 \%$ for Dom Helder Câmara. It was identified, in both settlements, the presence of families without legal ownership of the land, but that produce agroecologically and organically. This fact acquires great relevance, since this directly implies the development of the territorialization of the peasantry in these settlements.
\end{abstract}




\section{INTRODUÇÃO}

A Agroecologia surge como resposta às manifestações das crises sociais e ecológicas ocasionadas pela intensificação da lógica industrial na agricultura, que, ao se tornar hegemônica, seja de forma física, seja pelos valores da individualidade e da competitividade, trouxe uma tendência de homogeneização para as comunidades rurais (GUZMÂN, 2015).

A ampliação da concepção Agroecológica nos territórios faz referência à dimensão quantitativa, relacionada a mais agricultores, comunidades e organizações do campo agroecológico envolvidos nesse processo; mas também à dimensão qualitativa das estratégias de organização social, de construção do conhecimento local e de consolidação da Agroecologia como referência para o desenvolvimento dos territórios camponeses (VAL, 2019). Ou seja, significa a inclusão de mais camponeses em mais territórios na busca pela construção de sistemas alimentares justos e sustentáveis.

Há uma estreita relação entre a Agroecologia, a reconstrução dos territórios sob a ótica da sustentabilidade e o reconhecimento do papel dos camponeses no desenvolvimento territorial. Val et al. (2019) denominaram esses três componentes de vetores do método Camponês a Camponês $(\mathrm{CaC})$.

$\mathrm{O} \mathrm{CaC}$ é um processo horizontal, de troca de conhecimentos e experiências na busca por maior autonomia e controle dos territórios pelo público que compõe a agricultura de base familiar (ROSSET; TORRES, 2016). O CaC busca fazer frente à dominação dos territórios pela tendência homogeneizadora da agricultura industrial, que é operada atualmente por grandes corporações transnacionais do agronegócio (VAL; ROSSET, 2020).

No contexto da reforma agrária, a lógica de homogeneização da produção divide espaço com sistemas complexos e multiestratificados (LOPES et al., 2017), pois existem relações de produção agrícola e de geração de renda distintas entre os assentamentos, bem como entre as famílias de um mesmo assentamento (MOREIRA, 2020). A compreensão das diferentes dinâmicas camponesas nos assentamentos de reforma agrária permite elucidar como o campesinato se articula frente ao processo de homogeneização e dominação do capital no setor agroalimentar, denominado por Ploeg (2008) de impérios alimentares, e como esse grupo constrói estratégias descentralizadas para fornecer alimentos nos territórios, sobretudo aqueles de base agroecológica ou orgânica.

O presente texto tem como objetivo abordar o processo de ampliação da Agroecologia com base na experiência de um tipo de campesinato que busca se territorializar em áreas de reforma agrária. Para tal, buscar-se-á compreender como se dá o acesso à posse legal dos territórios pelos camponeses em assentamentos rurais e a contribuição dessa categoria de agricultores para consolidar a estratégia agroecológica.

Para obtenção de dados detalhados sobre as famílias assentadas, sobre a situação ocupacional nos assentamentos (posse legal da terra) e seus respectivos sistemas de produção, foi consultado o banco de dados do sistema Radis, integrante do Projeto Radis da Universidade Federal de Viçosa (UFV) em parceria com o Instituto Nacional de Colonização e Reforma Agrária (INCRA). As coletas foram realizadas nos meses de abril e maio de 2020. Informações qualitativas sobre a organização das famílias que estão inseridas no processo de transição agroecológica foram registradas em diário de campo (OLIVEIRA, 2014) durante os meses de janeiro a abril de 2021.

No campo científico, este estudo visa a contribuir para o diálogo entre os temas do território, da Agroecologia e do campesinato, no contexto dos assentamentos de reforma agrária, que são territórios politicamente conquistados, socialmente construídos e regulamentados pelo Estado.

(Re)territorialização camponesa em áreas de reforma agrária

Para compreender a amplitude das relações que ocorrem nos territórios e suas relações de poder e conflituosidade é necessário primeiramente compreender o conceito de espaço. $\mathrm{O}$ espaço é um conjunto formado entre os sistemas de objetos (material, visível) e os sistemas de ações (imaterial, processos, disputas, culturas). Segundo Santos (2006), a importância dada a um determinado espaço é construída em função do valor que a sociedade em algum determinado momento atribui a cada pedaço de matéria. Para o autor, quem atribui função e importância ao espaço é a sociedade.

O conceito de espaço não está desvinculado do território, pois o território é formado a partir das relações de poder que se estabelecem e que se apropriam do espaço (SILVA, 2015). Mas o espaço é anterior ao território. E, portanto, é por meio da apropriação do espaço que o ator social se territorializa (RAFFESTIN, 1993). Pois, sem 
o poder exercido por pessoas ou por grupos, o território não se define (BORDO, 2005).

Fernandes (2009), ao desenvolver uma tipologia dos territórios, descreveu o papel do Estado no exercício do poder, que, por meio de leis, decretos e demais normas, delimita seu espaço de governança. Delimitar é manifestar o poder numa área específica. No entanto, existem os territórios dentro do território, a exemplo das propriedades privadas, das terras indígenas e dos assentamentos de reforma agrária, que associam a regulamentação estatal com a construção social do território, porém com distintas territorialidades. A territorialização diz respeito ao conjunto de ações sociais realizadas durante o processo de ocupação de uma determinada área. Mas, não é constituída apenas por elementos materiais (HAESBAERT, 1997), pois:

Como processo de apropriação e controle, a territorialização se inscreve sempre num campo de poder, não apenas no sentido de apropriação física, material (através de fronteiras jurídico-políticas, por exemplo), mas também imaterial, simbólica (HAESBAERT, 1997, p. 40).

Rosset e Torres (2016) afirmam que existem duas estratégias de disputa pelo território que o campesinato e suas organizações devem enfrentar. A primeira está relacionada à conquista dos territórios materiais que se referem à luta por acesso, controle, uso e (re)configuração da terra. Nesse caso, é o território físico que consiste em comunidades, infraestrutura, solo, água, biodiversidade, montanha, vales, planícies e rios. A segunda faz referência aos territórios imateriais, que são o conjunto de ideias, construções teóricas e conceitos camponeses. Para esses autores, não existe território material camponês sem os territórios imateriais, e esse território imaterial também está constantemente em disputa.

Nesse sentido, existem territórios propícios a viabilizarem a organização de grupos sociais e ao mesmo tempo frearem o processo de desterritorialização camponesa, dentre os quais encontram-se os assentamentos rurais. Silva e
Cury (2015) afirmam que, no contexto da reforma agrária, as famílias assentadas, antes desterritorializadas e impedidas de construir outros modos de produção, têm a possibilidade de ressignificar a identidade camponesa a partir da mudança no regime de uso e posse do território conquistado. Para os autores, os assentamentos rurais apresentam características próprias, distintas de qualquer outra propriedade do meio rural. $\mathrm{O}$ fato é que os camponeses que ali residem possuem trajetórias de vida que permitem imprimir novas dinâmicas a esses territórios. "A forma pela qual é conquistada a propriedade tem um valor sentimental para o camponês, pois lhe confere a sobrevivência em meio ao sistema capitalista empreendido" (SILVA; CURY, 2015, p.25). E não é para menos, pois a luta pela terra é a luta por um determinado território (FERNANDES, 2008).

A terra conquistada por meio da criação de assentamentos rurais representa "novas formas de luta, de quem já lutou ou de quem resolveu lutar pelo direito à terra livre e ao trabalho liberto" (OLIVEIRA, 2007, p. 137). Representa também o ato de desconcentração da propriedade privada (MARTINS, 1999), quando esta não atende aos princípios legais retratados pela função social da terra. Fato que assegura aos camponeses o direito de reivindicar a alteração no uso e posse da terra e o dever do Estado de fiscalizar uma cláusula constituinte.

\section{ÁREA DE ESTUDO}

O estudo foi realizado em dois assentamentos de reforma agrária: o assentamento Flor do Bosque, localizado no município de Messias, e o assentamento Dom Helder Câmara, pertencente ao município de Murici, ambos no Estado de Alagoas (Figura 1). Residem oficialmente nesses assentamentos em torno de 75 famílias, sendo 33 famílias no Flor do Bosque e 42 famílias no Dom Helder Câmara (INCRA, 2017). 
Figura 1 - Localização dos assentamentos Flor do Bosque e Dom Helder Câmara nos municípios de Messias e Murici, respectivamente.

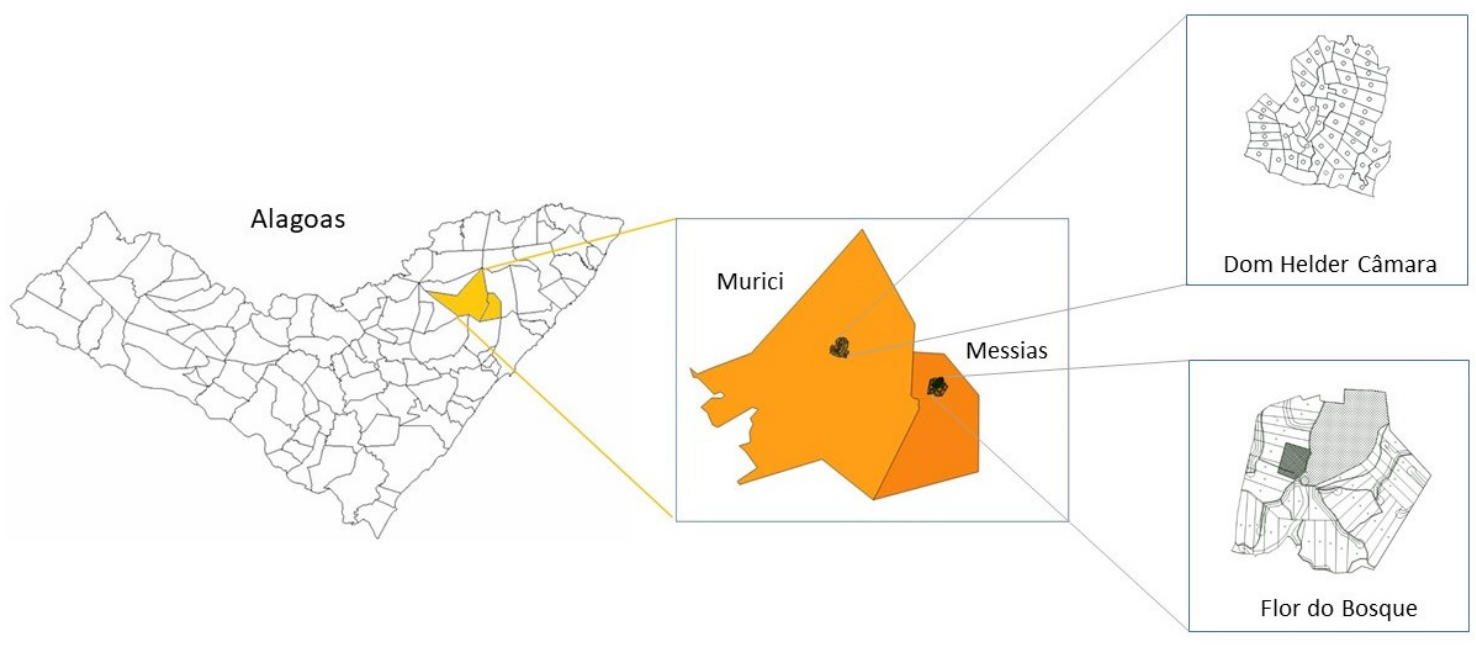

Fonte: Os autores (2021).

O acesso à terra em assentamentos de reforma agrária

O campesinato no Brasil tem na sua história a busca pelo acesso à terra, ou seja, pela possibilidade de conquistar um espaço produtivo e configurar um patrimônio familiar capaz de manter vivo seu modo de vida.

No entanto, o campesinato sempre foi impossibilitado de se desenvolver no Brasil, pois a opção pela concentração fundiária foi socialmente reconhecida e dominante em toda a sua história. Para o campesinato, restou resistir à margem do projeto de desenvolvimento adotado para o meio rural brasileiro e lutar pelo acesso ou permanência em seus territórios (WANDERLEY, 1996).

Essa realidade fez parte da criação dos dois assentamentos integrantes do presente estudo, ou seja, tanto o Assentamento Flor do Bosque quanto o assentamento Dom Helder Câmara foram conquistados a partir de processos de luta e de conflito nos territórios. O instrumento utilizado pelos camponeses foi a formação de acampamentos às margens dos imóveis rurais, com a finalidade de denunciar o não cumprimento da função social da propriedade. A inserção da função social da propriedade na política pública "possibilitou que famílias camponesas pudessem criar estratégias organizativas para ter acesso à terra e buscar a segurança jurídica sob os territórios conquistados" (GONDIM, 2018, p. 112).

Com a conquista da terra as famílias camponesas passaram a integrar o Sistema de Informações de Projetos de Reforma Agrária (SIPRA), responsável por manter o cadastro de cada beneficiário da reforma agrária em nível nacional.

Ser contemplado no SIPRA significa para as famílias a possibilidade de obter o primeiro acesso à documentação legal da terra, por meio do Contrato de Concessão de Uso (CCU). Cabe destacar, conforme assinalam Silva e Cury (2015), que historicamente a forma como esse grupo conseguiu ter acesso a esse bem comum foi por meio do arrendamento, da posse precária, ou mesmo como meeiros e trabalhadores rurais nas fazendas.

No entanto, o processo de territorialização camponesa é dinâmico e não se encerra com a conquista do assentamento. Fato é que o levantamento da situação ocupacional nas áreas estudadas evidenciou que há reivindicação pelo acesso à terra em áreas já constituídas oficialmente como assentamentos, ou seja, existem camponeses ocupando lotes desses assentamentos, reivindicando acesso ao programa de reforma agrária e a sua regularização no assentamento. Contudo, nessa situação, as ocupações desses lotes são consideradas oficialmente como irregulares (INCRA, 2019). Essas situações consideradas irregulares fazem referência às famílias ou pessoas que residem em lotes destinados à produção, dentro dos assentamentos, mas que não passaram pelo processo oficial de seleção. Essas famílias pleiteiam junto ao INCRA a regularização para tornarem-se oficialmente assentadas e poderem conquistar o acesso legal à terra (Tabela 1). 
Tabela 1 - Levantamento da situação ocupacional dos lotes nos assentamentos Flor do Bosque e Dom Helder Câmara

\begin{tabular}{lccccc}
\hline & $\begin{array}{c}\text { Capacidade do } \\
\text { Assentamento } \\
\text { assentamento } \\
\left(\mathrm{n}^{\mathbf{0}} \text { de famílias) }\right.\end{array}$ & $\begin{array}{c}c \\
\text { Assentadas } \\
\text { oficialmente } \\
\text { (SIPRA) }\end{array}$ & $\begin{array}{c}\text { Identificadas } \\
\text { pelo Sistema } \\
\text { Radis }\end{array}$ & Irregulares & Regulares \\
\hline Flor do Bosque & 35 & 33 & 37 & 10 & 27 \\
$\begin{array}{l}\text { Dom Helder } \\
\text { Câmara }\end{array}$ & 45 & 42 & 52 & 12 & 39 \\
\hline
\end{tabular}

Fonte: Os autores (2020).

A capacidade do assentamento faz referência ao estudo realizado pelo INCRA para identificar, com base em parâmetros técnico-produtivos, a quantidade de famílias que podem ser beneficiadas em cada assentamento. As famílias assentadas oficialmente são aquelas que constam na relação do SIPRA.

$\mathrm{O}$ assentamento Flor do Bosque possui um total de 350,8 hectares (ha), dos quais cerca de 70 ha são destinados à formação da Reserva Legal (RL), 10 ha às atividades ou empreendimentos coletivos e em torno de 270 ha aos lotes de produção, o que perfaz aproximadamente 7,0 ha para cada família. $O$ diagnóstico realizado com as 37 famílias identificadas no assentamento, divididas entre regulares (27) e irregulares (10), foi realizado em cada lote destinado à produção.

O Assentamento Dom Helder Câmara possui 303,53 ha, sendo 24,0 ha destinados à área de RL, cerca de 8,0 ha são exclusivos para atividades ou empreendimentos coletivos e em torno de 271 ha são divididos em lotes para produção, o que equivale a uma média de 5,0 ha por família.

Percebe-se em ambos os assentamentos um número maior de famílias do que a capacidade prevista oficialmente para a área. Isso decorre de três motivos principais: (1) a presença de famílias ocupando áreas de reserva legal; (2) a divisão dos lotes com outras famílias; (3) a necessidade de atualização da capacidade do assentamento após a divisão do imóvel rural em lotes. Nesses casos, são duas situações críticas que podem resultar na retirada de tais famílias da área do assentamento: primeiro, porque não há a previsão legal para assentar famílias em áreas destinadas à RL, posto que a função desse ambiente é a de "proporcionar a reabilitação dos processos ecológicos e promover a conservação da biodiversidade, bem como o abrigo e a proteção da fauna silvestre e da flora nativa" (BRASIL, 2012). Segundo, porque a divisão dos lotes pode reduzi-los a dimensões abaixo da fração mínima de parcelamento (FMP), que é a menor área em que um imóvel rural pode ser desmembrado. Para o município de Messias e de Murici, onde se localizam os assentamentos Flor do Bosque e Dom Helder Câmara, respectivamente, a FMP é de 4,0 ha. Desse modo, não há possibilidade de dividir e regularizar tais lotes em ambos os assentamentos, tornando a reivindicação das famílias que dividiram lote um processo não passível de ser assegurado pelos parâmetros da lei.

Para que a família camponesa tenha sua ocupação regularizada numa área de assentamento, ela deve atender cumulativamente aos seguintes critérios: ter iniciado a ocupação em data anterior a 22 de dezembro de 2015; possuir os critérios de elegibilidade na reforma agrária; assumir os débitos que porventura o antigo beneficiário tenha contraído perante o INCRA; além de não existir candidatos em lista de excedentes para o lote (INCRA, 2019). Os critérios de elegibilidade da reforma agrária configuram um perfil social que deve ser atendido pelas famílias que pleiteiam acessar o Programa Nacional de Reforma Agrária (PNRA), a saber: não ser ocupante de cargo público, embora a lei aponte certas exceções; não ter sido beneficiário da reforma agrária; não possuir outra propriedade rural, com exceção daqueles que possuem área insuficiente para o sustento próprio e da família; não possuir empresa; ser maior de 18 anos, ou emancipado na forma da lei civil; e não auferir renda de atividades não agrícolas superior a três salários mínimos mensais ou um salário mínimo per capita (INCRA, 2019).

Os critérios supracitados delimitam o perfil de quem pode acessar as áreas de reforma agrária, que são destinadas para famílias que não possuem condições financeiras para adquirir terra. E, embora a lei tenha criado certa regra de anistia para as ocupações realizadas antes de 22 de dezembro de 2015, e mesmo sem legislar sobre situações que envolveram relações comerciais no repasse da terra, os lotes de reforma agrária são inegociáveis, pois tratam de terras públicas das quais as famílias possuem a concessão de uso (CCU), regidas por contrato entre o governo federal e os(as) beneficiários (as). 
Cabe ressaltar, no entanto, que nem todos os que pleiteiam a regularização dos lotes em áreas de assentamentos podem ser considerados agricultores familiares ou camponeses. Nesses casos, o lote de reforma agrária é adquirido por meio da apropriação do espaço público, ou mesmo por meio da compra. Essa situação foi identificada no assentamento Flor do Bosque, totalizando sete ocupações irregulares na área de reserva legal, com construção de residências em alvenaria, pertencentes a não beneficiários da reforma agrária, parte dos quais utilizam as áreas ocupadas como chácara para lazer durante os finais de semana. Tal situação instaurou um ambiente de conflito no assentamento, razão pela qual não foi possível realizar o diagnóstico com as pessoas dessas ocupações.

$\mathrm{E}$, nesse caso, a realidade dos assentamentos - dividida entre camponeses beneficiários da reforma agrária e famílias que reivindicam uma parcela de terra em áreas de assentamentos já constituídos - evidencia que o processo de formação dos territórios se dá em diferentes escalas e em distintos contextos (FERNANDES, 2008). Essa conflituosidade pode ter um caráter temporário ou permanente, ou seja, a criação do assentamento configura a conquista, num determinado espaço de tempo, para determinadas famílias, mas pode configurar também o início da luta para outras famílias.

\section{A territorialização da concepção} agroecológica em áreas de reforma agrária

Nos assentamentos, as formas de organização, as estratégias produtivas e os tipos de relações que se estabelecem são tão diversos quanto diversos são os sujeitos que os compõem. $\mathrm{Na}$ realidade estudada, identificou-se que ambos os assentamentos possuem relação com a luta pela terra em nível local e global, bem como com processos organizativos relacionados à consolidação da estratégia agroecológica. Há a presença de organizações já estabelecidas nos territórios, como os movimentos sociais e as associações dos assentamentos, além da inserção de famílias em processos inovadores no Estado de Alagoas, como é o caso da certificação participativa por meio dos Sistemas Participativos de Garantia da Qualidade Orgânica (SPG) (Figura 2).

O SPG faz parte do arcabouço legal que define as estratégias para assegurar que um produto, processo ou serviço atende ao regulamento técnico definido para produção orgânica, podendo utilizar o selo de produto orgânico aceito em todo o território nacional (HIRATA et al., 2020).

As organizações presentes nos assentamentos apoiam e articulam as diferentes experiências dos(as) camponeses(as). Possuem também orientação para a produção de base agroecológica e viabilizam espaços de formação para o conjunto das famílias. A formação em Agroecologia realizada por organizações camponesas evidencia a multidimensionalidade da Agroecologia, que não se restringe aos aspectos produtivos, pois é também política (AZEVEDO et al., 2019), ciência aplicada, questionadora dos problemas da concentração fundiária (CAPORAL, 2015), bandeira de luta dos movimentos sociais e referência para a construção social dos territórios.

No aspecto técnico-produtivo, a Agroecologia não é unanimidade nos assentamentos, embora venha se materializando de forma paulatina por ações de grupos de camponeses. Ainda assim, há uma grande diversidade no cultivo de alimentos em ambos os assentamentos estudados, tanto de forma convencional (Tabela 2) quanto de forma agroecológica (Tabela 3). 
Figura 2 - Organizações sociais das quais fazem parte as famílias dos Assentamentos Flor do Bosque e Dom Helder Câmara.

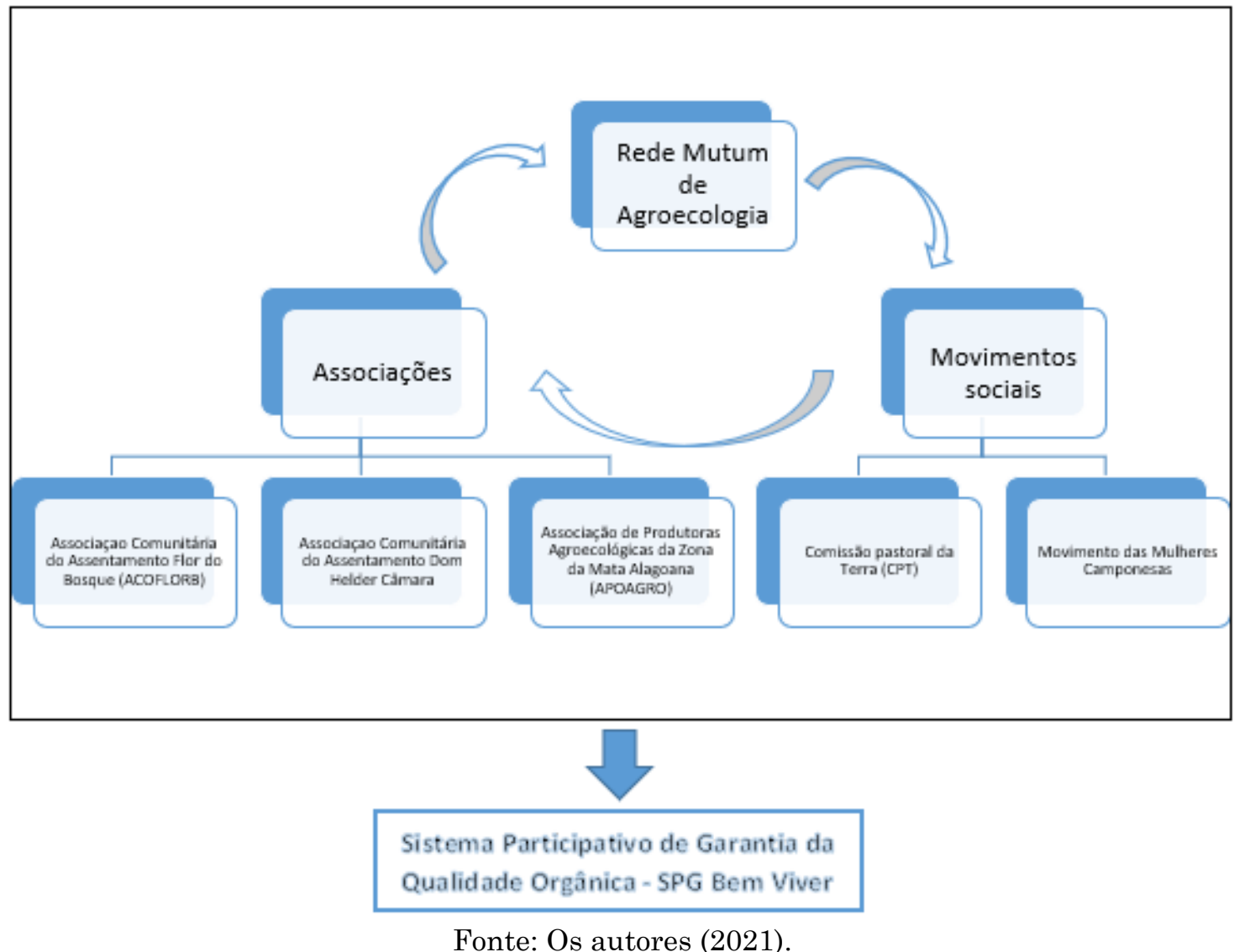

Tabela 2 - Produção agrícola convencional nos Assentamentos Flor do Bosque e Dom

\begin{tabular}{|c|c|c|c|}
\hline \multirow{2}{*}{$\begin{array}{c}\text { Principais } \\
\text { culturas }\end{array}$} & \multicolumn{2}{|c|}{$\begin{array}{c}\text { Produção } \\
(\mathrm{kg} / \mathrm{ano})\end{array}$} & \multirow{2}{*}{$\begin{array}{c}\text { Produção } \\
\text { Total } \\
\text { (kg/ano) }\end{array}$} \\
\hline & Flor do Bosque & Dom Helder Câmara & \\
\hline Abacate & - & 500 & 500 \\
\hline Abacaxi & 24.050 & 30.100 & 54.150 \\
\hline Acerola & 915 & 450 & 1.365 \\
\hline Banana & 25.875 & 35.900 & 61.775 \\
\hline Batata doce & 2.550 & 4.840 & 7.390 \\
\hline Caju & 158 & 100 & 258 \\
\hline Coco & 14.200 & 11.500 & 25.700 \\
\hline Feijão & 16.040 & 870 & 16.910 \\
\hline Goiaba & 360 & - & 360 \\
\hline Graviola & 200 & - & 200 \\
\hline Inhame & 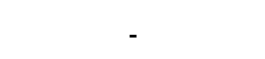 & 18.830 & 18.830 \\
\hline Jaca & - & 14.850 & 14.850 \\
\hline Laranja & 76.416 & 8.050 & 84.466 \\
\hline Limão & 355 & 600 & 955 \\
\hline Mandioca & 76.420 & 38.650 & 115.070 \\
\hline Manga & 500 & 750 & 1.250 \\
\hline Maracujá & 3.000 & 530 & 3.530 \\
\hline Milho & 7.740 & 6.490 & 14.230 \\
\hline Total & 248.779 & 173.010 & 421.789 \\
\hline
\end{tabular}


Tabela 3: Produção agrícola das famílias dos Assentamentos Flor do Bosque e Dom Helder Câmara em transição agroecológica - ano agrícola 2019/2020

\begin{tabular}{|c|c|c|c|}
\hline $\begin{array}{l}\text { Principais } \\
\text { culturas }\end{array}$ & $\begin{array}{l}\text { Flor do } \\
\text { Bosque }\end{array}$ & $\begin{array}{c}\text { Produção } \\
\text { (kg/ano) } \\
\text { Dom Helder } \\
\text { Câmara }\end{array}$ & Total \\
\hline Abacate & 380 & 2.850 & 3.230 \\
\hline Abacaxi & 3.500 & 23.300 & 26.800 \\
\hline Abóbora & - & 2.100 & 2.100 \\
\hline Abobrinha & 540 & - & 540 \\
\hline Acerola & 600 & - & 600 \\
\hline Alface & 540 & 62 & 602 \\
\hline Almeirão & 200 & - & 200 \\
\hline Banana & 6.519 & 13.850 & 20.369 \\
\hline Batata doce & 900 & 5.610 & 6.510 \\
\hline Caju & 108 & 120 & 228 \\
\hline Cebolinha & 540 & 62 & 602 \\
\hline Carambola & - & 100 & 100 \\
\hline Coco & 3.570 & 8.450 & 12.020 \\
\hline Coentro & - & 826 & 826 \\
\hline Couve & 990 & - & 990 \\
\hline Feijão & 120 & 280 & 400 \\
\hline Graviola & 36 & - & 36 \\
\hline Inhame & - & 54.030 & 54.030 \\
\hline Jaca & - & 5.460 & 5.460 \\
\hline Laranja & 13.912 & 5.350 & 19.262 \\
\hline Limão & - & 180 & 180 \\
\hline Mandioca & 18.100 & 65.500 & 83.600 \\
\hline Manga & 979 & 2.100 & 3.079 \\
\hline Maracujá & 480 & - & 480 \\
\hline Maxixe & 270 & - & 270 \\
\hline Melancia & 325 & - & 325 \\
\hline Milho & - & 16.440 & 16.440 \\
\hline Milho Pipoca & 160 & - & 160 \\
\hline Pimenta & 48 & - & 48 \\
\hline Pimentão & 48 & - & 48 \\
\hline Pitanga & 24 & - & 24 \\
\hline Plantas medicinais & - & 100 & 100 \\
\hline Quiabo & - & 145 & 145 \\
\hline Repolho & 210 & - & 210 \\
\hline Salsa & - & 360 & 360 \\
\hline Sapoti & - & 110 & 110 \\
\hline Tangerina & 96 & - & 96 \\
\hline Total & 53.195 & 207.385 & 260.580 \\
\hline
\end{tabular}

Fonte: Os autores (2020). 
Importa inicialmente assinalar a evidente relevância dos assentamentos de reforma agrária na produção de alimentos. $\mathrm{O}$ assentamento Flor do Bosque produz anualmente em torno de $301.974 \mathrm{~kg}$ de gêneros alimentícios e o assentamento Dom Helder Câmara, $380.395 \mathrm{~kg}$, correspondendo ao total de $682.369 \mathrm{~kg}$ de alimentos. Desse total, em torno de $38 \%(260.580 \mathrm{~kg})$ diz respeito à produção dos lotes cujas famílias camponesas aderiram ao processo de transição agroecológica (Figura 3).

A transição Agroecológica é um processo gradual de mudança, que envolve os aspectos da produção e do uso sustentável dos agroecossistemas, mas também das demais dimensões da Agroecologia, como a sociocultural e política, socioeconômica e ecológico-produtiva (GUZMÁN, 2015).

Figura 3 - Produção convencional e de transição agroecológica nos assentamentos Dom Helder Câmara e Flor do Bosque.

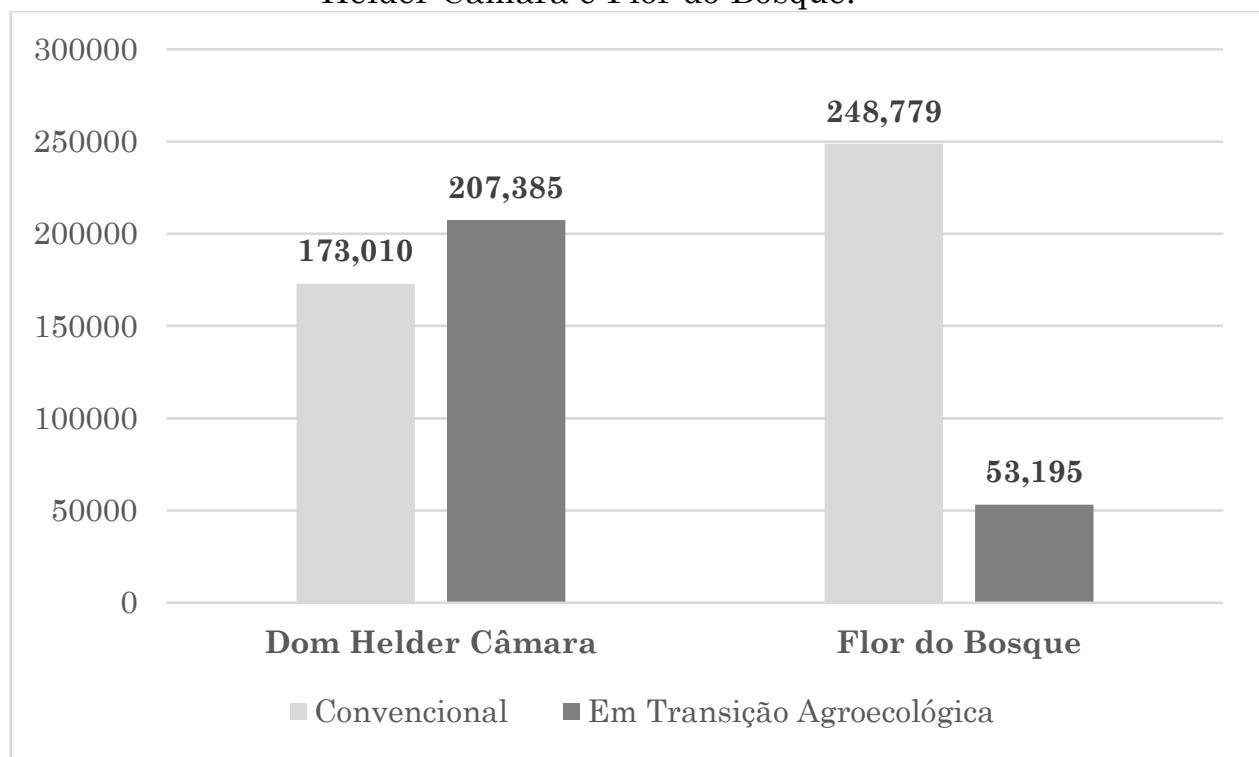

Fonte: Os autores (2020).

As famílias inseridas na produção de base agroecológica são aquelas que compõem o processo de criação do SPG, denominado de SPG Bem Viver. A estratégia de constituição do SPG resultou na formação de dois grupos em ambos os assentamentos: o grupo Embaúba, no assentamento Flor do Bosque, e o grupo Juçara, no assentamento Dom Helder Câmara. Os grupos integram uma instância do SPG, com autonomia para desenvolver o processo de certificação orgânica participativa dos seus pares. Nesse ínterim, novos camponeses dos assentamentos têm sido incluídos no contexto da produção de base agroecológica e orgânica.

No processo de constituição do SPG, a autonomia e o maior controle da produção e dos territórios pelos sujeitos locais são exercitados através do método camponês a camponês $(\mathrm{CaC})$. Numa relação entre pares, os camponeses fazem visitas às unidades de produção, apontam sugestões para a melhoria dos sistemas produtivos, trocam sementes e mudas, articulam circuitos curtos de comercialização para escoar os produtos, participam de formação sobre a Agroecologia e produção orgânica e consolidam novos modos de vida nos territórios.

$\mathrm{O} \mathrm{CaC}$ é uma das variadas metodologias utilizadas para estimular a construção do conhecimento agroecológico nos territórios e o desenvolvimento de agriculturas de base ecológica, com protagonismo e autonomia do(da) camponês(a) (VAL, 2019). A autonomia camponesa representa fortalezas da dinâmica social, é o oposto da dependência, que gera debilidade ou vulnerabilidade (ROSSET; BARBOSA, 2021).

A proposta de certificação orgânica participativa realizada pelo grupo Juçara e pelo grupo Embaúba está baseada em princípios que vão além dos parâmetros técnico produtivos, pois inserem elementos sociais que estimulam a maior cooperação entre os participantes (Figura 4). 
Figura 4: Princípios que estão orientando a constituição do SPG Bem Viver.

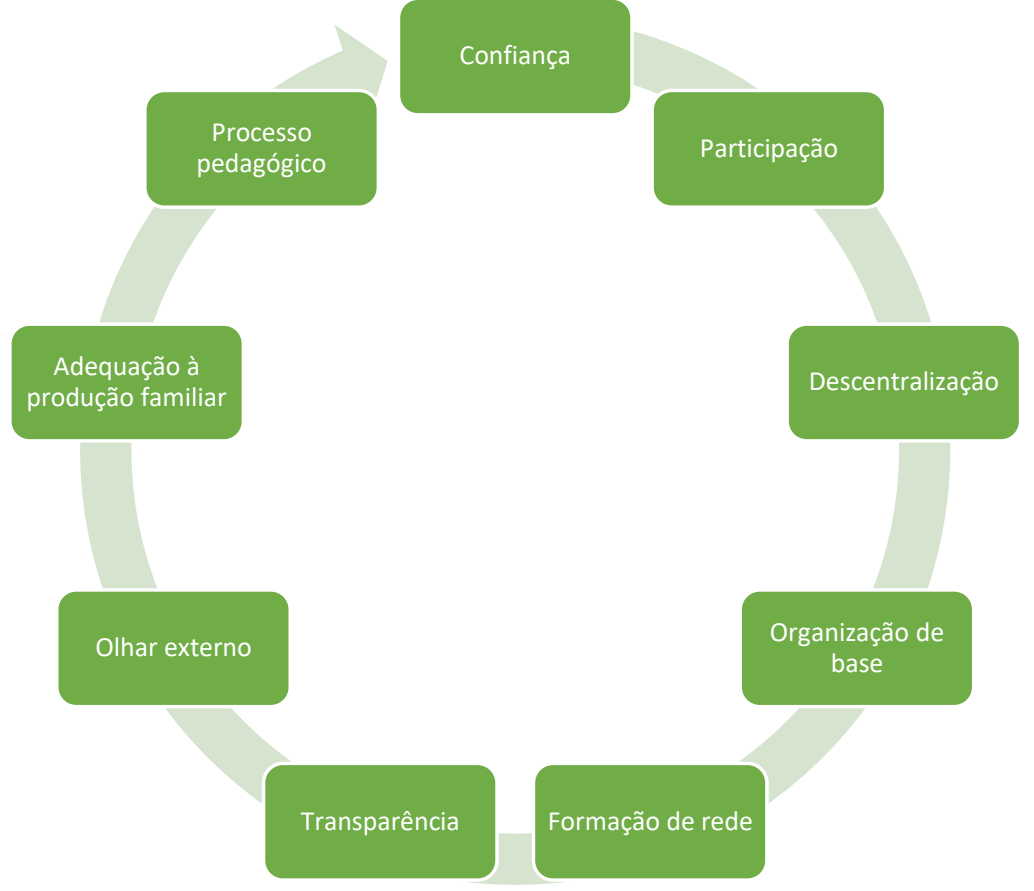

Fonte: Os autores (2021).

Esses princípios orientadores demarcam os aspectos da construção imaterial nos territórios. E têm nos seus objetivos um caráter transversal de busca por autonomia e controle social da produção de base agroecológica e orgânica pelos próprios camponeses(as). A produção desenvolvida pelos grupos Juçara e Embaúba apresenta grande relevância do ponto de vista da diversidade e do fornecimento significativo de alimentos para os territórios. Por exemplo, o grupo Embaúba produziu 90\% (26) dos 29 itens produzidos no assentamento Flor do Bosque, sendo que $48 \%$ (14) dos itens foram produzidos exclusivamente pelos seus integrantes.

Situação semelhante foi identificada no grupo Juçara, que produziu 92\% (23) dos 25 itens produzidos no assentamento, sendo que $39 \%$ (9 itens) são produzidos exclusivamente pelos camponeses do grupo.

Dois aspectos precisam ser destacados com relação a essas experiências. Primeiro, a diversidade em ambos os grupos, que é influenciada pela inserção dos camponeses em circuitos curtos de comercialização, o que promove a maior interação com consumidores e a experimentação de novos cultivos demandados por quem compra os alimentos. A articulação em torno da promoção da Agroecologia, a troca de experiências e de sementes nas atividades do SPG, também colaboram para ampliar a diversidade produtiva nos lotes. Na dinâmica do SPG, quando um novo cultivo é adotado, os camponeses compartilham a experiência com os demais integrantes do grupo por meio de fotos e vídeos. Essa partilha de experiências e inovações locais é prática de compartilhamento e solidariedade inerente ao processo de $\mathrm{CaC}$ (ROSSET; BARBOSA, 2021).

$O$ segundo destaque relevante de ser pontuado faz referência ao processo de territorialização camponesa no contexto da reforma agrária. Aí residem questões a serem registradas no presente trabalho, bem como apontamentos para estudos futuros sobre a temática. Isto é, partindo-se do pressuposto de que a reforma agrária contribui para superar uma fragilidade histórica do campesinato quanto à posse legal de suas terras (SILVA; CURY, 2015), o que garante a segurança jurídica de tais territórios, conforme apresentado na subseção anterior, não basta ser camponês para poder pleitear o acesso ao programa de reforma agrária, tampouco a Agroecologia e a produção orgânica são critérios de inclusão. Numa situação hipotética, o camponês do grupo Juçara ou do grupo Embaúba que esteja na situação irregular pode ter o direito de permanecer na terra negado e ser substituído por outra família de agricultores que não necessariamente irá desenvolver experiências de produção de base agroecológica.

A territorialização camponesa de base agroecológica em áreas de reforma agrária é, portanto, um tema que necessita maior aprofundamento à luz dos requisitos legais, mas também dos aspectos multidimensionais que envolvem a proteção desses territórios para o desenvolvimento do modo de vida camponês. No 
presente estudo, demonstramos a relevância do camponês assentado para a produção de alimentos, seja convencional ou de base agroecológica, para a geração de autonomia nos territórios, no acesso e controle social de políticas públicas, a exemplo da constituição do SPG, mas destacamos, com base nos dados apresentados, a contribuição do campesinato na reorganização de territórios que anteriormente sofreram um processo de homogeneização e concentração de terras, fruto do modelo de desenvolvimento baseado na agricultura de base industrial.

A estratégia de formação do SPG consubstanciada no método $\mathrm{CaC}$, além de almejar o acesso ao processo de certificação orgânica, busca também estabelecer o maior controle do território pelos camponeses e ampliar experiências de base agroecológica com a incorporação de novos membros aos grupos, mesmo que a situação de regularidade do camponês na reforma agrária ainda não tenha sido alcançada.

Por fim, corroborando os apontamentos de Rosset e Torres (2016), vale salientar que a disputa por territórios realizada pelos camponeses busca não somente a conquista da terra, mas também a disputa por ideias e projetos de desenvolvimento territorial mais inclusivos. A ampliação da Agroecologia é um debate que vem permeando a literatura, primeiro, pela sua ampliação em área e em número de agricultores (scaling-out); segundo, pela institucionalização em políticas de suporte (scaling-up). Em ambas as estratégias de ampliação da Agroecologia, a reforma agrária está inserida como instrumento capaz de materializar experiências baseadas no saber e na prática camponesa.

\section{CONSIDERAÇÕES FINAIS}

O campesinato mantém ativa a caminhada pelo acesso à terra. A terra é compreendida como um meio para alcançar a maior autonomia, seja na gestão dos territórios conquistados, seja na organização produtiva. Discutimos no presente texto, a partir da experiência dos assentamentos Dom Helder Câmara e Flor do Bosque, como a reforma agrária possibilita estabelecer processos de territorialização do campesinato; primeiro, pela existência de marcos legais que possibilitam a destinação de terras aos agricultores; segundo, pela organização coletiva do campesinato em processos que envolvem o acesso e a permanência na terra.
No entanto, é necessário aprofundar o fato de que também há camponeses que reivindicam o acesso à terra em assentamentos já constituídos. As experiências em Agroecologia e produção orgânica realizadas nessas parcelas de terra são tão vulneráveis quanto a permanência dessas famílias no território, pois é preciso se enquadrarem num determinado perfil definido pela legislação da reforma agrária para não serem desterritorializadas. Se com a produção de base agroecológica e orgânica é possível ampliar e diversificar a oferta de alimentos para a população, questionamos: é possível incorporar esse parâmetro na legislação que rege os critérios de elegibilidade para a reforma agrária, bem como para a regularização de lotes com ocupação irregular? São questões para aprimorar a política pública de reforma agrária que indicamos como necessárias para maior aprofundamento em futuros ensaios sobre a temática.

Por fim, vale salientar que proteger os territórios camponeses significa também a oportunidade de ampliar as experiências em Agroecologia, a partir da geração de alimentos diversificados e do desenvolvimento de estratégias locais para assegurar o controle social da produção, a exemplo do processo de criação do SPG consubstanciado na metodologia $\mathrm{CaC}$.

A tenacidade do camponês em seu território faz com que esse grupo desenvolva experiências capazes de incidir sobre a dialética entre os territórios materiais e imateriais. Os territórios com a presença do campesinato e de suas experiências em Agroecologia, além de produzirem alimentos, produzem novos valores e novos princípios, para além da lógica dominante e homogeneizante implementada pela agricultura de base industrial.

\section{REFERÊNCIAS}

AZEVEDO, H. P.; ASSIS, W. S. de; SOUSA, R. da P. Agroecossistemas de camponeses agroextrativistas na Amazônia brasileira: uma reflexão a partir da Agroecologia política. Revista Brasileira de Agroecologia, Dois Vizinhos (PR), v. 14, n. 2, p. 51-64, 2019. https://doi.org/10.33240/rba.v14i2.22950

BORDO, A. A.; SILVA, C. H. P. da; NUNES, M.; BARBOSA, T.; MIRALHA, W. As Diferentes Abordagens do Conceito de Território. In: VI Semana de geografia, 2005, Presidente Prudente. VI Semana de Geografia, 2005.

BRASIL. Lei $\mathrm{n}^{\circ} 12.651$ de 25 de maio de 2012 . Disponível

http://www.planalto.gov.br/ccivil_03/_ato2011-

2014/2012/lei/112651.htm. Acesso: 08 fev. 2021. em: 
CAPORAL, F. R. Extensão rural e agroecologia: para um novo desenvolvimento rural, necessário e possível. Camaragibe, PE: Ed. do coordenador, 2015.

FERNANDES, B. M. Entrando nos territórios do território. In: PAULINO, E. T.; FABRINI, J. E. (org.). Campesinato e territórios em disputa. São Paulo: Expressão Popular, 2008. p. 273-302.

FERNANDES, B. M. Sobre a tipologia de territórios. In: SAQUET, M. A.; SPOSITO, E. S. (Org.) Territórios e Territorialidades: teorias, processos e conflitos. São Paulo: Expressão Popular, 2009. p. 197-216.

GONDIM, C. H. N. Entre vitórias e derrotas: a função social da terra na constituição de 1988 versus o direito de propriedade absoluto. Uma análise do caso da Usina Cambahyba. In: Revista de Direito Agrário: 30 Anos da Constituição Federal de 1988. Brasília: INCRA, p. 107-130, 2018

GUZMÁN, E. S. La participación em la construcción histórica latino-americana de la Agroecología y sus niveles de territorialidade. Politica y Sociedad, Madrid, v. $52, \quad$ n. $\quad 2, \quad 2015$. https://doi.org/10.5209/rev_POSO.2015.v52.n2.45205

HAESBAERT, R. Des-territorialização e identidade: a rede "gaúcha" no Nordeste. Niterói: EDUFF, 1997.

HIRATA, A. R.; ROCHA, L. C. D. da; BERGAMASCO, S. M. P. P. Panorama nacional dos sistemas participativos de garantia. In: HIRATA, A. R.; ROCHA, L. C. D. (Org.) Sistemas participativos de garantia no Brasil: histórias e experiências. Pouso Alegre: IFSuldeminas, 2020. p. 13-48.

INCRA, 2017. Instituto nacional de Colonização e Reforma Agrária. Painel dos Assentamentos. Disponível em: https://painel.incra.gov.br/sistemas/index.php Acesso: 01 fev. 2021.

INCRA, 2019. Instrução Normativa $\mathbf{n}^{\circ} \mathbf{9 9}$, de 30 de dezembro de 2019. Disponível em: https://www.in.gov.br/web/dou/-/instrucao-normativan-99-de-30-de-dezembro-de-2019-236098411. Acesso: 08 fev. 2021.

LOPES, A. W. P.; CARMO, M. S. do; BERGAMASCO, S. M. P. P.; FERRANTE, V. L. S. B. Assentamentos rurais e práticas pedagógicas: uma análise em duas modalidades diferenciadas de assentamento. Espaço de Diálogo e Desconexão, Araraquara, v.9, n.1 e 2, 2017. https://doi.org/10.11606/issn.25952536.v26i2p41-55

MARTINS, J. de S. Reforma Agrária: o impossível diálogo sobre a história possível. Tempo Social, São Paulo, v. 11, n. 2, p. 97-128, 1999.

MOREIRA, F. G. As relações produtivas nos assentamentos rurais do Município de Nova Andradina/MS. Revista Nera, Presidente Prudente, v. 23, n. 55,2020 . https://doi.org/10.21527/2237. 6453.2020.50.72-88

OLIVEIRA, A. U. de. Modo de produção capitalista, agricultura e reforma agrária. São Paulo: Faculdade de Filosofia, Letras e Ciências Humanas (FFLCH), 2007.

OLIVEIRA, R. de C. M. de. (Entre)linhas de uma pesquisa: o diário de campo como dispositivo de (in)formação na/da abordagem (auto)biográfica. Revista Brasileira de Educação de Jovens e Adultos, v2., n.4, p. 69-87, 2014.

PLOEG, J. D. V. D. Camponeses e Impérios Alimentares. Rio Grande do Sul: Editora da UFRGS, 2008.

RAFFestin, C. Por uma Geografia do Poder. São Paulo: Editora Ática S.A., 1993.

ROSSET, P. M.; BARBOSA, L. P. Autonomía y los movimientos sociales del campo em América Latina: um debate urgente. Aposta, Madrid, n. 89, p. 8-31, 2021.

ROSSET, P. M.; TORRES, M. E. M. Agroecología, território, recampesinización y movimentos sociales. Revista de Investigación Científica, San Cristóbal de Las Casas, México, v. 25, n. 47, p. 275-299, 2016.

SANTOS, M. A Natureza do Espaço: Técnica e Tempo, Razão e Emoção. São Paulo: Editora da Universidade de São Paulo, 2006.

SILVA, D. dos S.; CURY, M. J. F. A Identidade Camponesa dos Assentamentos do MST no Brasil. Revista Geographia Opportuno Tempore, Londrina-PR, v. 1, n. 4, p. 22-35, 2015.

SILVA, P. A. S. Território: abordagens e concepções. Boletim DATALUTA, Presidente Prudente, n. 96, 2015.

VAL, V.; ROSSET, P. M.; LOMELI, C. Z.; GIRALDO, O. F.; ROCHELEAU, D. Agroecology and La Via Campesina I. The symbolic and material construction of agroecology though the dispositive of "peasant-topeasant" processes. Agroecology and Sustainable Food Systems. v. 43, n. 7-8, 2019, p. 872-894. https://doi.org/10.1080/21683565.2019.1600099

VAL, V. Campesina/o a Campesina/o: Un dispositivo para la masificación de la agroecologia. Congreso Argentino de Agroecología, Mendonza, 2019, p. 1095-1098.

VAL, V. ROSSET, P. M. Campesino a Campesino: Educación campesina para la resistência y la transformación agroecológica. Revista Brasileira de Educação do Campo. Tocantinópolis, v. 5, n.1, 2020. https://doi.org/10.20873/uft.rbec.e10904

WANDERLEY, M. de N. B. Raízes históricas do campesinato brasileiro. In: Encontro anual da ANPOCS, Caxambu, 1996.

\section{CONTRIBUIÇÃO DOS AUTORES}

José Ubiratan Rezende Santana concebeu o estudo, coletou, analisou os dados e redigiu o texto. Ana Maria Dubeux Gervais é coorientadora do primeiro autor, analisou os dados, realizou a correção do artigo e sugeriu ajustes ao texto. Jorge Luiz Schirmer de Mattos é orientador do primeiro autor, analisou os dados, realizou a correção do artigo e sugeriu ajustes ao texto.

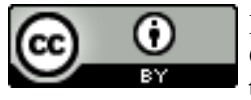

